\title{
Frontal Fibrosing Alopecia and Increased Scalp Sweating: Is Neurogenic Inflammation the Common Link?
}

\author{
Matthew J. Harries ${ }^{a}$ Sharon Wong ${ }^{b}$ Paul Farrant ${ }^{c}$ \\ a Dermatology Centre, University of Manchester, Salford Royal NHS Foundation Trust, Salford, ${ }^{b}$ Department of \\ Dermatology, Homerton University Hospital NHS Foundation Trust, London, and ' Department of Dermatology, \\ Brighton and Sussex University Hospitals NHS Trust, Brighton, UK
}

\section{Established Facts}

- Frontal fibrosing alopecia (FFA) is an uncommon inflammatory scarring hair loss disorder.

- It predominantly affects post-menopausal women, although there are growing reports of pre-menopausal women and men being affected.

\section{Novel Insights}

- Localized increased scalp sweating is observed in a group of women with FFA.

- Possible association between increased sweating and scalp inflammation is presented.

\section{Key Words}

Alopecia $\cdot$ Inflammation · Sweating $\cdot$ Substance P .

Calcitonin gene-related peptide

\begin{abstract}
Frontal fibrosing alopecia (FFA) is an uncommon scarring hair loss disorder that is characterized by a band-like recession of the frontal hair line with eyebrow hair loss. We present a series of patients with FFA and increased sweating predominantly localized to the scalp, and potential explanations for this association are discussed. We hypothesize that the reported increase in sweating seen in our patients may be in part related to the inflammatory process occurring locally within the skin, either inducing a local axonal sweating reflex or through direct modulation of sweat gland secretion by neuropeptides.
\end{abstract}

(c) 2016 S. Karger AG, Basel
(C) 2016 S. Karger AG, Basel

2296-9195/16/0014-0179\$39.50/0

\section{Introduction}

Frontal fibrosing alopecia (FFA) is an uncommon scarring hair loss disorder that is characterized by a bandlike recession of the frontal hair line that is often associated with eyebrow, face and body hair loss [1]. The condition is permanent as the hair follicles (HFs) in the zones of alopecia are progressively destroyed and replaced by scar-like fibrous tissue [2]. FFA was first described by Kossard [2] in 1994, and since then, the incidence of the condition appears to be increasing [3-7].

We present a series of patients with FFA with associated increased sweating of the scalp and discuss potential explanations for this phenomenon. 


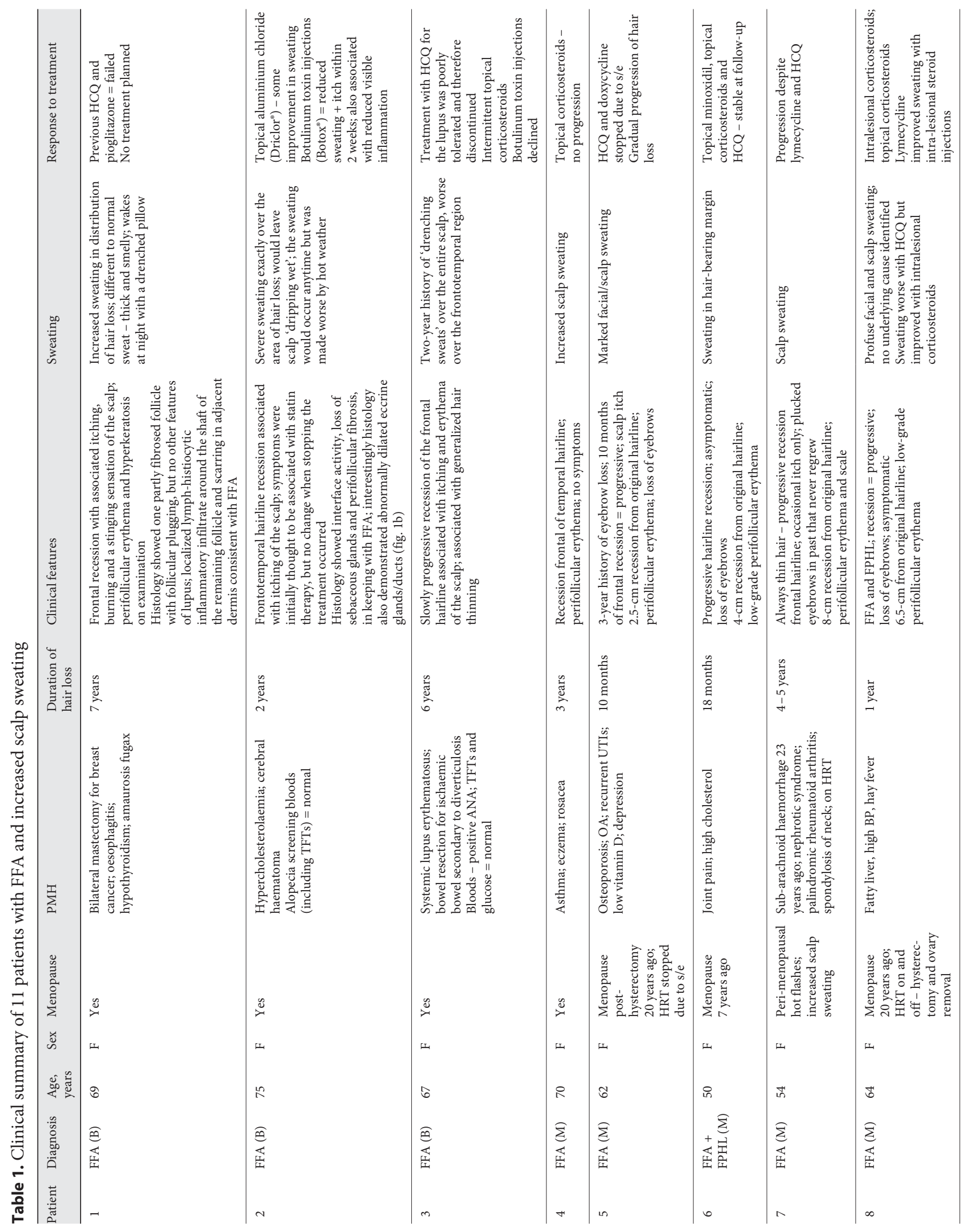




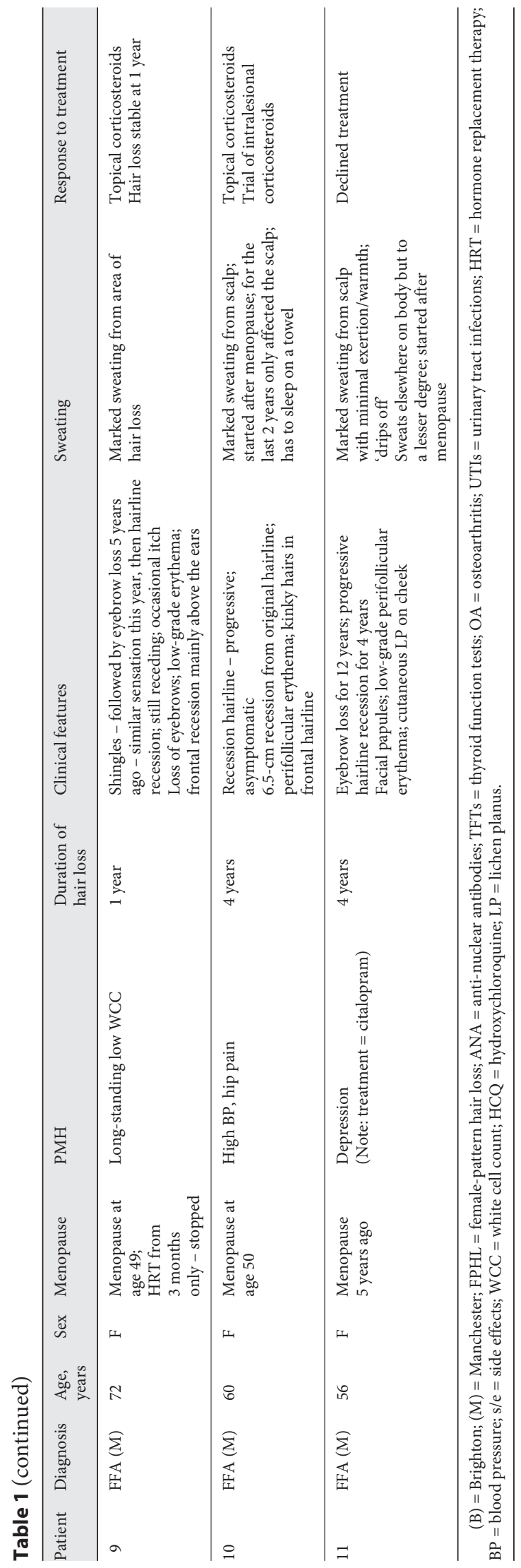

Frontal Fibrosing Alopecia and Sweating

\section{Description of Cases}

All patients were identified retrospectively from two specialist hair clinics (Manchester and Brighton). The diagnosis of FFA was confirmed by clinical evaluation (fig. 1a) and scalp biopsy. Each patient complained of increased sweating of the scalp, in some cases specifically localized to the area of alopecia. The sweating was sufficiently troublesome for patients to proffer the symptom without direct questioning. In 2 females, the sweating was of such severity that they would sleep on a towel each night to absorb excess sweat. In 1 case treated with localized botulinum toxin injections to the scalp, not only did sweating improve but reduction in itch and diminished visible inflammation was also observed. Clinical details for each patient are presented in table 1 .

\section{Discussion}

Sweat is produced by eccrine sweat glands of which humans have several million distributed over nearly the entire body surface, with the palms, soles and scalp having the highest density. Each eccrine sweat gland consists of a secretory coil deep in the dermis and a duct that conveys the secreted sweat to the skin surface. Traditionally, the sweat gland is viewed as anatomically separate from the pilosebaceous unit; however, a recent morphological study suggests a much closer physical association with the HF, with the secretory coil consistently situated below the insertion of the arrector pili muscle close to the outer root sheath [8]. The primary function of the eccrine unit is thermoregulation, which is accomplished through the cooling effects of evaporation of sweat from the skin's surface. Sweating is a reflex function that is controlled through the sympathetic nervous system. Stimulation of eccrine sweat production is predominantly mediated through post-ganglionic production of acetylcholine, although locally generated neuropeptides, such as substance $\mathrm{P}$ and calcitonin gene-related peptide (cGRP), act to regulate sweat secretion rates [9].

Hyperhidrosis (or excessive sweating) can be classified in a number of ways including: (1) whether this process only affects sweating or occurs as part of a wider disease process ('primary' or 'secondary'); (2) according to the distribution of sweating ('generalized' or 'focal'), or (3) according to the source of neural impulse ('cortical', 'hypothalamic', 'medullary', 'spinal cord' or 'local axon reflex'). For example, localized hyperhidrosis affecting the palms, soles and/or axillae (a presentation most familiar to dermatologists) would be classified as a primary, focal and cortical hyperhidrosis. A local axon reflex occurs when a stimulus applied to one branch of a nerve sets up an impulse that moves centrally to the point of division 
Fig. 1. a Frontal hairline recession and loss of eyebrows. Close inspection reveals 'band-like' scarring alopecia with peri-follicular erythema and scale in the frontal hair margin (Patient 2). b Histopathology from the same patient reveals peri-follicular inflammation and fibrosis (thick arrow) with a dilated eccrine gland in close proximity to the affected HF (thin arrows).
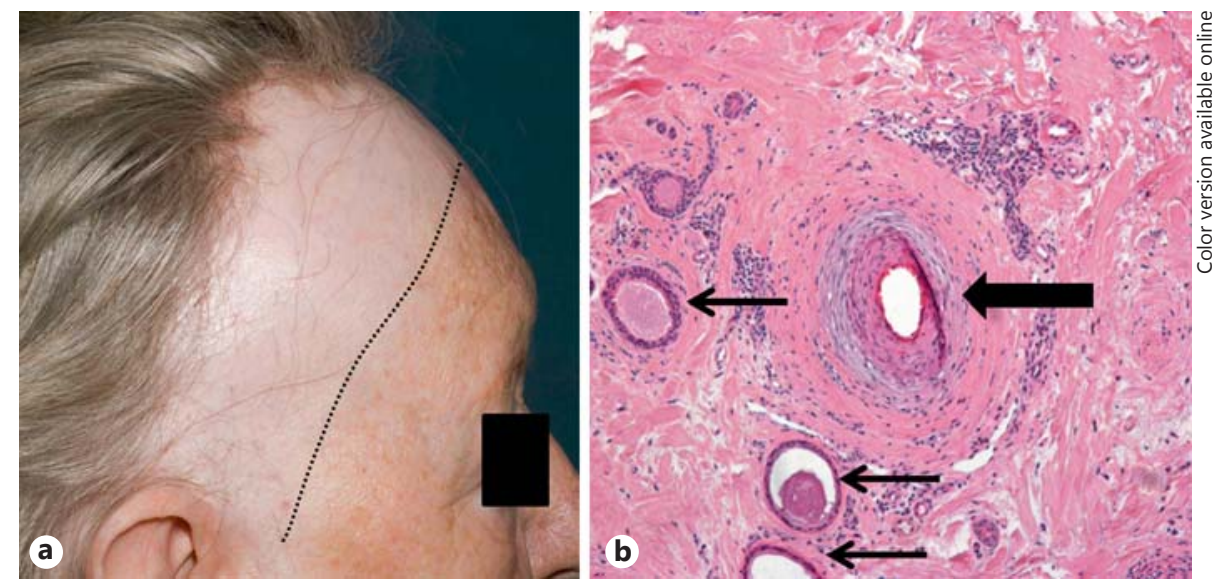

of the nerve where it is then reflected back down the other branch to the effector organ. It is a peripheral reflex that bypasses higher integration centres in the central nervous system. Blood vessels, sweat glands and mast cells are most important effectors of local axon reflexes affecting the skin.

FFA was first described by Kossard [2] in 1994 and is generally regarded as a variant of lichen planopilaris (LPP) based on similarity in lesion morphology and indistinguishable histological features $[3,4]$. A key event in the permanent HF loss seen in lesional FFA is the destruction of epithelial HF stem cells $[2,10]$, likely due to a Th1biased inflammatory response and loss of HF immune privilege [11]. However, it is still unclear what predisposes to this inflammatory attack; genetic susceptibility may be important, whereas environmental factors may explain the recent identification, pattern and growing incidence of the condition [12].

One hypothesis for the pathogenesis of scarring alopecias is neurogenic skin inflammation [2]. Evidence for this comes from animal models where stressed mice show increased expression of neuropeptides (including substance $\mathrm{P}$ ), increased degranulation of mast cells, and loss of HF immune privilege [13-17]. Further, we know that in mice, nerve-derived hedgehog signaling maintains a subset of bulge stem cells expressing Gli1, suggesting a vital role of nerve signaling in supporting HF stem cell function [18]. In humans, total numbers of mast cells along with the proportion of degranulating mast cells are increased in the peri-follicular bulge region in LPP/FFA [19]. Early work examining nerve fibre density and expression of substance $\mathrm{P}$ and cGRP in FFA is currently limited to meeting proceedings (i.e. unpublished) but suggests variability in the expression of these neuropep- tides between lesional and non-lesional scalp skin as well as differences between LPP and FFA disease groups [20]. In the clinic, many patients cite stress as a potential trigger for their hair loss [21].

Interestingly, many of these neurogenic skin inflammatory signals, particularly substance P and cGRP, are also important in sweat regulation [22]. We hypothesize that the reported increase in sweating seen in our patients may be in part related to the inflammatory process occurring locally within the skin, either inducing a local axonal sweating reflex or through direct modulation of sweat gland secretion by neuropeptide effects.

In 1 patient who responded to anti-sweating therapy in the form of botulinum toxin injections, improvements in scalp itch and visible inflammation were also observed. In a separate patient, the excess sweating improved with anti-inflammatory measures in the form of corticosteroid injections into the affected scalp skin. These observations highlight the potential interaction between (neurogenic) inflammation and sweating and suggest possible avenues for future therapy development (e.g. botulinum toxin injections, topical capsaicin, etc.). The role of neurogenic inflammation (and botulinum toxin therapy) has been proposed in a number of other inflammatory conditions, including psoriasis $[23,24]$.

Another observation of note is the histological identification of dilated eccrine glands seen in 1 patient (fig. 1b). Eccrine gland changes are not well described in cicatricial alopecia, but it is likely that any change to these glands would represent a secondary phenomenon from either localized blockage of drainage (e.g. induced by localized fibrosis/inflammation) and/or gland atrophy (e.g. through inflammation-induced apoptosis/pressure effects). Interestingly, a number of reports describe the 
presence of syringomas in scalp biopsies for hair loss, including cases of cicatricial alopecia, although whether these are truly associated or just represent a coincidental finding requires further study (see Deen et al. [25] for a review of the literature).

Although the above arguments plausibly explain the apparent association between increased sweating and FFA, the following should also be considered: (1) coincidence: do these patients just have a localized primary hyperhidrosis or even just physiological levels of sweating, which has become more evident due to the loss of hair? Eyebrow loss in FFA means that sweat is no longer prevented from falling into the eyes, and wet hair exaggerates the appearance of the hair loss, with both features drawing attention to the sweating; or (2) menopause effects: all patients described here are post-menopausal women with a few also experiencing increased face and/or body sweating in addition. However, other menopausal symptoms were generally absent (except hot flashes in 1 patient), and many were already well past the peri-menopause period at the time when symptoms typically began [26]. Further, FFA is recognized to also affect face and body hair growth by the same process as on the scalp [7, 27].

We present 11 women with FFA and associated scalp sweating. We propose that the mechanism for this may be through neurogenic inflammation and changes to localized neuropeptide signaling regulating sweating respons- es. Due to the retrospective nature of case identification and reliance on the patients providing information about their sweating unprompted, it is possible that increased sweating may in fact be more common than this report suggests (e.g. 8 of 116 FFA patients in the Manchester cohort) and should in future be specifically enquired about. Further work is required to confirm this potential association by objective quantification of hyperhidrosis and exploration of the underlying mechanisms, with particular focus on the role of neurogenic skin inflammation.

\section{Acknowledgements}

We thank Dr. Mark Taylor for the histological assessment of scalp biopsies. We also thank Dr. Enrique Poblet and Prof. Ralf Paus for their helpful comments about eccrine glands and the HF.

\section{Statement of Ethics}

As the study presents a retrospective case, no ethical approval is required.

\section{Disclosure Statement}

The authors have no conflicts of interest to disclose.

\section{References}

1 Harries MJ, Trueb RM, Tosti A, Messenger AG, Chaudhry I, Whiting DA, Sinclair R, Griffiths CE, Paus R: How not to get scar(r)ed: pointers to the correct diagnosis in patients with suspected primary cicatricial alopecia. $\mathrm{Br}$ J Dermatol 2009;160:482-501.

2 Harries MJ, Paus R: The pathogenesis of primary cicatricial alopecias. Am J Pathol 2010; 177:2152-2162.

3 Kossard S: Postmenopausal frontal fibrosing alopecia. Scarring alopecia in a pattern distribution. Arch Dermatol 1994;130:770-774.

4 Kossard S, Lee MS, Wilkinson B: Postmenopausal frontal fibrosing alopecia: a frontal variant of lichen planopilaris. J Am Acad Dermatol 1997;36:59-66.

5 MacDonald A, Clark C, Holmes S: Frontal fibrosing alopecia: a review of 60 cases. J Am Acad Dermatol 2012;67:955-961.

6 Tan KT, Messenger AG: Frontal fibrosing alopecia: clinical presentations and prognosis. Br J Dermatol 2009;160:75-79.
7 Vano-Galvan S, Molina-Ruiz AM, SerranoFalcon C, Arias-Santiago S, Rodrigues-Barata AR, Garnacho-Saucedo G, Martorell-Calatayud A, Fernandez-Crehuet P, Grimalt R, Aranegui B, Grillo, E, Diaz-Ley B, Salido R, Perez-Gala S, Serrano S, Moreno JC, Jaen P, Camacho FM: Frontal fibrosing alopecia: a multicenter review of 355 patients. J Am Acad Dermatol 2014;70:670-678.

8 Poblet E, Jimenez-Acosta F, Hardman JA, Escario E, Paus R: Is the eccrine gland an integral, functionally important component of the human scalp pilosebaceous unit? Exp Dermatol 2016;25:149-150.

9 Kumazawa K, Sobue G, Mitsuma T, Ogawa T: Modulatory effects of calcitonin gene-related peptide and substance $\mathrm{P}$ on human cholinergic sweat secretion. Clin Auton Res 1994;4: 319-322.

10 Pozdnyakova O, Mahalingam M: Involvement of the bulge region in primary scarring alopecia. J Cutan Pathol 2008;35:922-925.
11 Harries MJ, Meyer K, Chaudhry I, E Kloepper J, Poblet E, Griffiths CE, Paus R: Lichen planopilaris is characterized by immune privilege collapse of the hair follicle's epithelial stem cell niche. J Pathol 2013;231:236-247.

12 Aldoori N, Dobson K, Holden C, McDonagh AJ, Harries M, Messenger AG: Frontal fibrosing alopecia - possible association with leaveon facial skin care products and sunscreens; a questionnaire study. Br J Dermatol 2016 (accepted for publication).

13 Peters EM, Liotiri S, Bodo E, Hagen E, Biro T, Arck PC, Paus R: Probing the effects of stress mediators on the human hair follicle: substance P holds central position. Am J Pathol 2007;171:1872-1886.

14 Peters EM, Arck PC, Paus R: Hair growth inhibition by psychoemotional stress: a mouse model for neural mechanisms in hair growth control. Exp Dermatol 2006;15:1-13. 
15 Peters EM, Handjiski B, Kuhlmei A, Hagen E, Bielas H, Braun A, Klapp BF, Paus R, Arck PC: Neurogenic inflammation in stress-induced termination of murine hair growth is promoted by nerve growth factor. Am J Pathol 2004; 165:259-271.

16 Peters EM, Kuhlmei A, Tobin DJ, MullerRover S, Klapp BF, Arck PC: Stress exposure modulates peptidergic innervation and degranulates mast cells in murine skin. Brain Behav Immun 2005; 19:252-262.

17 Siebenhaar F, Magerl M, Peters EM, Hendrix S, Metz M, Maurer M: Mast cell-driven skin inflammation is impaired in the absence of sensory nerves. J Allergy Clin Immunol 2008; 121:955-961.

18 Brownell I, Guevara E, Bai CB, Loomis CA, Joyner AL: Nerve-derived sonic hedgehog defines a niche for hair follicle stem cells capable of becoming epidermal stem cells. Cell Stem Cell 2011;8:552-565.
19 Harries M: The Immunopathobiology of lichen planopilaris; thesis, University of Manchester, Manchester, 2011.

20 Hordinsky M, Doche I: Nerves and scarring alopecia disorders: a novel treatment approach. Cicatricial Alopecia Workshop 23rd World Congress of Dermatology 2015. Vancouver, June 2015.

21 Chiang YZ, Bundy C, Griffiths CE, Paus R, Harries MJ: The role of beliefs: lessons from a pilot study on illness perception, psychological distress and quality of life in patients with primary cicatricial alopecia. Br J Dermatol 2015;172:130-137.

22 Peters EM, Ericson ME, Hosoi J, Seiffert K, Hordinsky MK, Ansel JC, Paus R, Scholzen TE: Neuropeptide control mechanisms in cutaneous biology: physiological and clinical significance. J Invest Dermatol 2006;126: 1937-1947.
23 Saraceno R, Kleyn CE, Terenghi G, Griffiths $\mathrm{CE}$ : The role of neuropeptides in psoriasis. $\mathrm{Br}$ J Dermatol 2006;155:876-882.

24 Borodic GE, Acquadro M, Johnson EA: Botulinum toxin therapy for pain and inflammatory disorders: mechanisms and therapeutic effects. Expert Opin Investig Drugs 2001;10: 1531-1544.

25 Deen K, Curchin C, Wu J: Incidental Syringomas of the scalp in a patient with scarring alopecia. Case Rep Dermatol 2015;7:171-177.

26 Archer DF, Sturdee DW, Baber R, de Villiers TJ, Pines A, Freedman RR, Gompel A, Hickey M, Hunter MS, Lobo RA, Lumsden MA, MacLennan AH, Maki P, Palacios S, Shah D, Villaseca P, Warren M: Menopausal hot flushes and night sweats: where are we now? Climacteric 2011;14; 515-528.

27 Chew AL, Bashir SI, Wain EM, Fenton DA, Stefanato CM: Expanding the spectrum of frontal fibrosing alopecia: a unifying concept. J Am Acad Dermatol 2010;63:653-660. 